\title{
The health and welfare of dogs belonging to homeless people.
}

\author{
David Leonard Williams and Sarah Hogg ${ }^{1}$
}

Abstract

A significant number of homeless people own dogs, with these animals contributing to the well-being of their owners by providing emotional support and in many cases, a reason for living as well as acting as what might be termed a social catalyst, improving bonds between their owners. Yet many consider that homeless people should not be allowed, let alone encouraged to keep a dog. They consider that living with homeless people must have a negative impact on the dog's health and welfare compared to that of a dog owned by people with a home. Here we sought to determine the health and welfare of dogs owned by homeless people, comparing 50 dogs owned by homeless people with 50 owned by people living in a home. In contradistinction to the negative view noted above, we found that dogs owned by homeless people were healthy animals, less likely to be obese, had fewer behaviour issues such as aggression to strangers and separation anxiety when compared to dogs owned by people living in a conventional home. We suggest that these findings should be taken into account when deciding whether a homeless person with a dog should be allowed into a hostel, and indeed the general attitude of the public to homeless people living with a dog by their side on the street.

HIGHLIGHTS

Dogs owned by homeless people are generally healthy with few behaviour problems.

Even though lower body condition scores have been found, only one dog was found to be underweight

Behaviour is not generally an issue in homeless peoples' dogs

Pet Behaviour Science | 2016, Vol. 1, 23 - 30

David Leonard Williams and Sarah Hogg

1. Department of Veterinary Medicine. University of

Cambridge

Paper Research

Email:

dlw33@cam.ac.uk

United Kingdom

Keywords:

dog; health; homeless; pet; welfare

\section{INTRODUCTION}

Homelessness affects many thousands of people in the UK and is a growing problem. Reliable statistics are difficult to access as these individuals are often difficult to reach, moving between temporary accommodation and the streets (Fitzpatrick et al. 2000). In autumn 2015, it was estimated that there were 2700 rough sleepers on the UK streets, with $21 \%$ of the national total bedding down in London (Thames Reach, 2015). In addition there are hundreds of people without a permanent home sleeping in hostels, or in sub-standard or temporary accommodation.

Homelessness has significant negative impacts both upon those who are homeless and the society which renders them thus (Communities and Local Government. 2011; Sakelaropoulos et al. 1998). They are at greater risk of poor health outcomes (O'Grady and Gaetz 2004; Frankish et al. 2005) and increased use of mental health and addiction services than homed individuals (Caton et al. 1995; Grimm and Maldonado 
1995; Bogard et al. 1999; Burt et al. 2001; Taylor et al. 2004). It is not just that homeless people lack the physical protection which a house affords; their predicament is a destructive experience leaving them without social and legal dimensions, roots and identity. They are often bereft of a sense of belonging and the emotional well-being which living in a home provides (Crisis, 2011, Homeless Link. 2009).

The human-animal bond promotes the welfare of both parties (Davis and Balfour 1992, Russow 2002, Labreque and Walsh 2011) with the physical and emotional benefits of pet ownership being well documented (Edney1993; Serpell 1991; Wilson and Turner 1998; SCAS 1999; Staats et al. 1999). Dogs can act as a 'social catalyst' and provide the emotional support and social relationships often lacking in homelessness (Robinson 1997; Rew 2000). Dogs are the most popular pets belonging to the homeless, benefitting homeless people by facilitating communication with others (Menteith 2001; Kidd and Kidd 1994), combating the intense feelings of isolation that homelessness can give. Dog ownership can be a vital method in coping with suicidal thoughts (Rew 2000) and reducing drug use common amongst the homeless (Baker 2001) probably through fear of imprisonment which would necessitate relinquishing the dog (Taylor et al. 2004). Around one third of the homeless population turn to crime, with minor offences such as shoplifting being common (Ballintyne 1999). Dog ownership appears to reduce the likelihood of a homeless person committing a crime (Taylor et al. 2004) again potentially because imprisonment necessitates loss of the animal. Crucially, dogs give their owner a sense of responsibility; in 2000, Rew found that they inspired better decision making amongst young homeless people. Taylor, Williams and Gray (2004) found that homeless people are strongly attached to their pets and depend upon them for companionship, stability and security, and showed that the homeless were generally more empathetic towards animals than the general public.

Having made all those positive comments, it is a sad fact that the majority of homelessness projects in the UK do not accept or admit dogs (Dogs Trust Project 2007) although a growing number are now allowing pets to be accommodated. Although they badly need the support of such services, many homeless people are unable to receive help simply because they own a dog (Singer 1995). Programme facilitators are often concerned about dogs' potential behavioural problems, such as toileting and aggression and perceived health issues such as fleas and worms (Hope Project 2015). For the homeless, many of whom have experienced multiple forms of loss, being forced to give up their pet in order to access accommodation may cause further emotional trauma (Labrecque and Walsh 2011). The majority of homeless dog owners would rather remain homeless than accept accommodation that would not allow their pets (Hart and Zasloff 1995; Baker 2001). A dog, therefore, can be the limiting factor that keeps a homeless person on the streets permanently (Masters 1998; Menteith 2001).

There is little information in the literature concerning homelessness and companion animals (Labrecque and Walsh 2011). Whilst the primary focus of such literature has rightly been the welfare and health of the owner, there is a lack of literature regarding the health or welfare of the dogs themselves. Here we present the results of a clinical health examination of 50 dogs owned by homeless people and 50 owned by settled individuals together with details of discussion with the owners on the health and welfare of their pets.

\section{METHODS}

\section{Questionnaire and 'Health Check' Examination}

A purposive convenience sampling technique was used to recruit dogs and their owners for a standardized clinical 'health check' examination and questionnaire regarding the dog's care. 50 homeless dog-owner pairs were approached whilst on the street in Cambridge and London; 38 non-homeless participants were approached whilst walking their dogs in the same sampling areas and 12 whilst presenting their healthy dogs for vaccination or post-neuter consultations at the RSPCA clinic, run by the veterinary school in Cambridge. All homeless people with dogs encountered while walking the streets of these two cities were asked whether they would be prepared to take part in the study. Without exception they agreed after the reasons for the survey were explained and time taken to gain their trust and confidence. Most 
seemed happy that positive attention was being paid to them and their pet. Similarly homed owners walking their dogs were generally happy to be involved with only three people saying they were too busy to stop and talk.

Owners were asked the questions noted in table 1 ; their dog's age, how long they had owned the dog and its source, about its diet and exercise regime, and any routine veterinary care received. The owners gave a verbal consent to the dogs being examined after which the dogs were then given a brief clinical examination following a sheet detailing each area to be examined (Figure 1) concluding with a conversation with the owner where any problems were discussed. The dog's body condition score was assessed using standard techniques previously reported (Laflamme 1997) both visually and by palpating how easily the ribs can be felt, as shown on the World Small Animal Veterinary Association website (WSAVA, 2013). Rectal temperature was not taken but cardiac auscultation and abdominal palpation was possible.

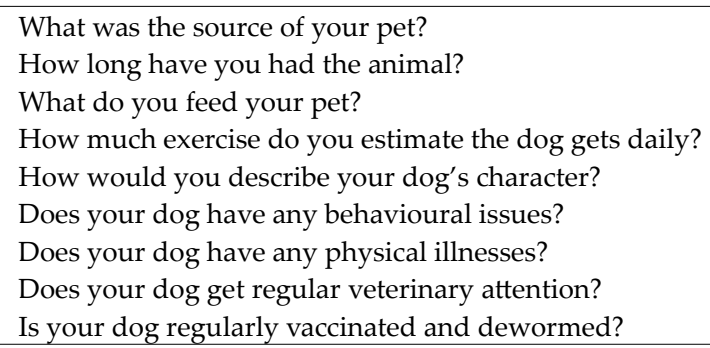

Table 1. Questions asked of owners during informal discussion

Finally, the dogs' demeanour was noted as being friendly, outgoing and approachable, neutral, shy and withdrawn or overtly aggressive and owners were asked about any behavioural problems that their dog showed. Interviews were conducted with a technique sensitive to the emotional perspective of homelessness.

The study received ethics approval from the University of Cambridge Veterinary School ethics committee. All participants gave informed consent. No reward was offered for participation in either health checks or the survey, and responses throughout were anonymous.

\section{RESULTS}

A significant difference was found between the ages of dogs belonging to homeless and non-homeless individuals (homed: mean \pm standard deviation $5.4 \pm 3.98$, $\mathrm{N}=50$; homeless: $3.7 \pm 2.9, \mathrm{~N}=50, \mathrm{p}=0.03$ ) with dogs belonging to homeless people being significantly younger. No homeless-owned dogs surveyed was greater than 12 years of age.

\section{Source of dog, and length of time in owner's possession}

A considerable difference in reported sources of dogs was noted, with $80 \%$ of dogs belonging to settled owners being purchased compared to only $4.5 \%$ of dogs belonging to homeless people $(\mathrm{p}<0.01)$. All of these purchased dogs were purchased before the owners became homeless. Whereas the great majority of non-homeless-owned dogs had been with their owners since 8 weeks of age or earlier $(70 \%)$ and were purchased from private sellers or breeders $(66 \%)$, most homeless-owned dogs were acquired later in life (70\%) and were reported to be strays (39\%) or acquired from friends, several of whom had died or were going into prison (27\%). $69 \%$ of dogs belonging to settled owners were in multi-pet household, whereas $81 \%$ of dogs belonging to homeless owners were the only pet $(\mathrm{p}<0.05)$.

\section{Diet}

Whereas most settled dog owners used a commercial, branded dog food as the main constituent of their dogs' diet (38/50), the majority of homeless dog owners chose a supermarket own-brand food (36/50). Whilst $95.5 \%$ of homeless owners fed their dogs a dry diet, only $46 \%$ of settled owners chose a predominantly dry diet, with the remainder either feeding a mixed, or entirely wet diet.

\section{Exercise}

Many homeless people found it hard to quantify how much exercise their dogs get in a day, as they are out and about being walked for several hours. $77 \%$ of homeless owners mentioned extra walks or specific park visits. Dogs are often kept off their leads, and so are free to wander as they wish. $88 \%$ of dogs belonging 
to settled owners, however, were subject to a twice daily routine of walks, usually lasting 20-30 minutes. $22 \%$ of owners reported that this varied with work or social commitments. The remainder of dogs are not walked daily, or are kept in the house permanently.

\section{Demeanour}

Dogs belonging to homeless people were very significantly more likely to be described as 'quiet, but friendly' $\left(\chi^{2}=10.3, \mathrm{DF}=1, \mathrm{p}=0.001\right)$, whereas those belonging to settled people were more likely to display aggression towards the person giving them a health check $\left(\chi^{2}=4.65, \mathrm{DF}=1, \mathrm{p}=0.031\right)$. Dogs belonging to

Date:

Location:

No:

\section{Clinical Exam and Questionnaire}

Breed:

Age:

Sex:

Body condition score:

General history: (how long owned, where from, diet, exercise, etc.)

\begin{tabular}{|c|c|c|c|c|c|c|c|}
\hline & NAD & Abn. & No Exam & & NAD & Abn. & No Exam \\
\hline 1. Appearance & $\square$ & $\square$ & $\square$ & 7. Locomotion & $\square$ & $\square$ & $\square$ \\
\hline 2. Attitude & $\square$ & $\square$ & $\square$ & 8. Musculoskeletal & & & \\
\hline 3. Head \& Face & & & & - joints & $\square$ & $\square$ & $\square$ \\
\hline - eyes & $\square$ & $\square$ & $\square$ & - bones & $\square$ & $\square$ & $\square$ \\
\hline - ears & $\square$ & $\square$ & $\square$ & - musdes & $\square$ & $\square$ & $\square$ \\
\hline - nose & $\square$ & $\square$ & $\square$ & - paws & $\square$ & $\square$ & $\square$ \\
\hline 4. Mouth & & & & -anus & $\square$ & $\square$ & $\square$ \\
\hline - muc. mem & $\square$ & $\square$ & $\square$ & -vulva/testicles & $s \square$ & $\square$ & $\square$ \\
\hline - gingiva & $\square$ & $\square$ & $\square$ & -mamm/penis & $\square$ & $\square$ & $\square$ \\
\hline - teeth & $\square$ & $\square$ & $\square$ & 10. Abdominal cavity & $\square$ & $\square$ & $\square$ \\
\hline - tonsils & $\square$ & $\square$ & $\square$ & 11. Respiratory & $\square$ & $\square$ & $\square$ \\
\hline 5. Lymph nodes & $\square$ & $\square$ & $\square$ & 12. Cardiovascular & $\square$ & $\square$ & $\square$ \\
\hline 6. Skin & $\square$ & $\square$ & $\square$ & 13. Nervous system & $\square$ & $\square$ & $\square$ \\
\hline
\end{tabular}

Extra detail, INC OWNERS CONCERNS:

Behaviour? (Human interaction, barking, toileting, separation issues)

Access to veterinary care?

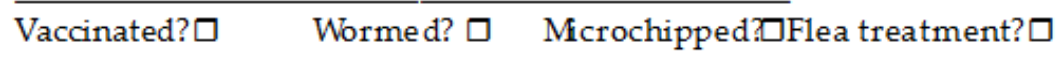


settled owners were also significantly more likely to be hyperactive or openly disobedient during the interview $\left(\chi^{2}=3.68, D F=1, p=0.055\right)$. No significance was found for dogs being friendly and moderately outgoing $\left(\chi^{2}=1.61, \mathrm{DF}=1, \mathrm{p}=0.205\right)$, friendly and very outgoing $\left(\chi^{2}=0.865, \mathrm{DF}=1, \mathrm{p}=0.352\right)$, nervous and withdrawn $\left(\chi^{2}=1.31, \mathrm{DF}=1, \mathrm{p}=0.284\right)$ or defensive of their owner $\left(\chi^{2}=0.491, \mathrm{DF}=1, \mathrm{p}=0.484\right)$.

\section{Behavioural issues}

Homeless-owned dogs were significantly less likely to have behavioural problems reported than settledowned dogs $\left(\chi^{2}=24.2, \mathrm{DF}=1, \mathrm{p}<0.001\right)$. Dogs belonging to settled owners were significantly more likely to display inappropriate barking $\left(\chi^{2}=9.2, \mathrm{DF}=1\right.$, $\mathrm{p}=0.002)$ or chewing and destructive behaviour $\left(\chi^{2}=7.60, \mathrm{DF}=1, \mathrm{p}=0.006\right)$, and significantly more likely to have toileting issues $\left(\chi^{2}=5.02, \mathrm{DF}=1, \mathrm{p}=0.025\right)$. No significance was found for incidents of aggression $\left(\chi^{2}=2.63, \mathrm{DF}=1, \mathrm{p}=0.105\right)$, separation anxiety $\left(\chi^{2}=2.42\right.$, $\mathrm{DF}=1, \mathrm{p}=0.102)$, excessive nervousness $\left(\chi^{2}=0.476\right.$, $\mathrm{DF}=1, \mathrm{p}=0.494)$, pulling on the lead or showing frequent attention seeking behaviour $\left(\chi^{2}=2.73, \mathrm{DF}=1\right.$, $p=0.099$, for each category).

\section{Physical health}

A significant difference was noted between the body condition score (BCS) of dogs belonging to the homeless and non-homeless communities (homed: $5.7 \pm 1.23, \mathrm{~N}=50$; homeless: $4.3 \pm 0.97, \mathrm{~N}=50, \mathrm{p}=<0.01$ ) where 5 is considered an acceptable BCS and as value above 5 as over-weight (Laflamme 1997). Homelessowned dogs had a significantly lower BCS, but spread over a healthier range than for non-homeless-owned dogs, which have a far higher chance of being overweight or obese.

There was no significant difference between the numbers of physical abnormalities found in homelessowned or settled owned $\operatorname{dogs}\left(\chi^{2}=0.713, \mathrm{DF}=1\right.$, $p=0.933$ ), nor were there any significant differences found for the following conditions: skin and ear problems $\left(\chi^{2}=0.094, \mathrm{DF}=1, \mathrm{p}=0.889\right)$, ectoparasites $\left(\chi^{2}=2.42, \mathrm{DF}=1, \mathrm{p}=0.102\right)$, wounds, serious scarring or infected feet $\left(\chi^{2}=3.3, D F=1, p=0.069\right)$, gastrointestinal problems $\left(\chi^{2}=2.34, \mathrm{DF}=1, \mathrm{p}=0.126\right)$, cardiac problems $\left(\chi^{2}=2.73, \mathrm{DF}=1, \mathrm{p}=0.099\right)$, arthritis and other locomotor problems $\left(\chi^{2}=3.21, \mathrm{DF}=1, \mathrm{p}=0.073\right)$, congenital defects $\left(\chi^{2}=3.68, \mathrm{DF}=1, \mathrm{p}=0.055\right)$, senile or degenerative changes $\left(\chi^{2}=0.713, \mathrm{DF}=1, \mathrm{p}=0.933\right)$.

\section{Routine veterinary procedures}

Registration and regular access to veterinary care was far higher amongst settled dog owners, with 95.5\% reporting routine use of a veterinarian. 15 of the 42 dogs cited a charity clinic, as opposed to a private veterinarian, as their usual provider of veterinary care. Amongst homeless participants, 27\% reported no access to veterinary care, $46 \%$ stated that although they didn't regularly access veterinary care they would use a charity clinic were it needed, and $27 \%$ named a clinic or facility with which they were a registered, regular client. Dogs belonging to settled owners were more likely to be vaccinated with $78 \%$ of dogs having up-todate cover, as opposed to $39 \%$ of homeless dogs $(p<0.01) .16 \%$ of dogs belonging to settled owners were reported to have recently lapsed vaccinations, compared to $18 \%$ of homeless-owned dogs. Only 3 out of 50 settled owners chose not to vaccinate, compared to 18 of 44 homeless owners. $80 \%$ of settled owners reported regularly worming their dogs, $6 \%$ of having wormed but with lapsed treatments and $14 \%$ deciding not to treat their dogs; compared to $30 \%, 30 \%$ and $40 \%$ of homeless owners respectively. Microchipping was reported to be a more common practice amongst settled owners with $62 \%$ microchipping their dogs, compared to $22 \%$ of homeless owners. Many homeless owners cited a lack of fixed address as an obstacle to useful microchipping. Several homeless owners who had microchipped their dogs had done so before becoming homeless, and now had the incorrect contact details on record. $50 \%$ of settled owners reported regularly treating their dogs for fleas, $10 \%$ having given treatments which were now overdue and $40 \%$ deciding not to treat; compared to $27 \%, 25 \%$ and $48 \%$ of homeless owners respectively.

\section{DISCUSSION}

Contrary to much opinion, it does not appear from this study that dogs belonging to homeless people are less healthy than those belonging to settled owners, although they do predominantly experience a different 
range of health conditions unique to the conditions in which they live on the streets. This is not what the public would seem to believe, with most people expecting dogs belonging to homeless people to be in poorer health than those belonging to the nonhomeless.

Aside from fleas, skin complaints affecting homelessowned dogs tended to be calluses, and other physically induced conditions, whereas non-homeless-owned dogs tended to suffer from allergy, atopy and masses such as histiocytomas and lipomas. Gastrointestinal complaints in homeless dogs tended to be ownerreported diarrhoea. There is a high chance this could be caused by worms, but could also be due to the higher probability of dietary indiscretion or an irregular diet. The only gastrointestinal problem reported in the nonhomeless population was motion sickness; not a complaint that homeless dogs are likely to suffer from as they rarely, if ever, travel in vehicles. Although the statistics showed the numbers of these dogs as insufficient to provide a significant difference between populations, dogs with cardiac, endocrine and senile or degenerative changes were found in the homed, but not the homeless population. This may be because dogs with severe cardiac and endocrine problems cannot survive on the street and dogs on the street do not live to be old enough to develop problems related to senility.

The population of dogs belonging to homeless people would appear to have different characteristics than that belonging to settled owners. The majority are strays, as opposed to purpose-bred and purchased, and the population has a younger average with dogs at the oldest end of the spectrum (over 12 years of age) missing entirely from our population sample. In homeless people, the average life expectancy is just 42 years of age (Crisis 2002), compared to 78.0 years for settled males and 82.1 years for settled females in England (ONS 2010). The cold, damp, unsanitary conditions they are forced to live in leave them more susceptible to disease and injury. If such conditions have such a drastic impact on human life expectancy, then they are likely to impact on animals kept in the same way.

Dogs belonging to the homeless in this study had significantly fewer behavioural problems than those belonging to settled owners. Several factors could explain this. Dogs belonging to the homeless have a much greater range and degree of contact both with people and other dogs, so are better socialized. They receive more exercise than dogs belonging to settled owners, tending to be more constantly wandering with additional park visits to allow them to run around freely, as opposed to subject to a two-outings-a-day regime which is subject to their owners work and social commitments. As they are not frequently left alone for long periods of time, they do not suffer from separation anxiety, and as they are usually the only pet or companion, they receive plenty of individual attention and mental stimulation. Only just under a third of the survey participants supported this result.

Homeless dogs had a significantly lower BCS than the non-homeless population. However, only one dog was found to be underweight, and this was matched by a similar dog amongst the housed population. Many dogs in the homed population were overweight, or obese. Homeless dogs were healthier in this respect, which may be because they receive more exercise, are less likely to be overfed or given calorie-rich food because of financial reasons, or because living outside in the cold means they have a higher basal energy demand.

Clearly examining the animals on the street places limits on the degree of evaluation possible but physical examination including thoracic auscultation, abdominal palpation, assessment of pulse and respiration are all possible to give a reasonably detailed clinical examination close to what might be possible in a veterinary consulting room.

Other issues involve the impossibility of performing ancillary tests. Without the use of faecal egg counts, for example, it was impossible to screen dogs for endoparasites and without the opportunity to perform skin scrapes for mites, wet paper tests for flea dirt or cytological impression smears, the presence of ectoparasites was difficult to ascertain. The inability to evaluate faecal samples for worm egg counts similarly made detection of gastrointestinal parasitic disease. This would be useful in future extensions of this research to confirm or disregard gastrointestinal 
parasites as the causes of reported diarrhoea cases, and to test the hypothesis that endoparasites are more common in dogs belonging to the homeless. Additionally, although dogs suffering from symptomatic cardiac problems as noted from auscultation, demonstration of a pulse deficit and a history of poor exercise tolerance were noted in a small number of homed dogs, it is difficult to fully evaluate a dog's cardiac status, or to detect subtle abnormalities, on the street.

Another significant issue concerns the fact that it is difficult when interviewing people about the care of their pet to be sure of an entirely truthful answer. Whilst many settled owners were happy to chat, particularly in the veterinary surgery at the RSPCA, about their animals' veterinary problems, homeless participants were sometimes reluctant to admit such issues. Understandably, they are wary of people wishing to document what may be seen as neglectful on their part. It is difficult for the interviewer to build up necessary trust within a short time frame. Settled owners sometimes seemed to exaggerate the amount of exercise their dog receives, as they also did not wish to be perceived as neglectful. Behavioural issues seemed to be under-reported, with owners telling anecdotes where the dog exhibited a problem, or with dogs sometimes exhibiting behavioural problems during the health check, followed by the owner reporting no problems with their dog. In such cases, issues were noted as part of the health check.

Literacy weaknesses are inevitable with most questionnaires, leading to varying interpretations of questions. This may have been an issue with the electronic survey, although the opportunity to directly contact the researchers, or leave a comment at the end helped to alleviate this. Whilst working with the homeless community, a more phenomenological approach and more flexible interview questions may be useful to allow interviewees to explain their choices (e.g. diet, access to veterinary care) more formally. An ethnographic technique would be the most useful method, in order to ensure a good basis for trust. For any future work, it would be useful to work in partnership with shelters and/or outreach schemes in order to survey a wider number of homeless pet owners, and to perform health checks in more amenable surroundings. Offering worming medication, flea treatments, food or toys may be beneficial to dogs of participating homeless owners.

\section{CONCLUSION}

The purpose of this study was to explore the health status of dogs belonging to homeless people; an area that has received very little attention in scientific or sociological literature. The key findings demonstrated that dogs belonging to the homeless are not significantly less healthy than those belonging to nonhomeless individuals. They have lower body condition scores, but this is because the non-homeless dog population tends towards being overweight or obese. They also appear to have fewer behavioural problems.

Further investigation into the health of dogs belonging to homeless people would be invaluable in improving homeless-accessible veterinary services, improving public education and counterbalancing the negative stigma often attached to homeless pet owners. It would also raise awareness of professionals in the field who are often concerned about dogs' behaviour and health issues that making their facilities pet-friendly is not tantamount to inviting in a human health risk, or viable criticism that they are supporting owners who do not properly care for their animals. These dogs do not exhibit behaviour that is likely to discourage other users of such services from doing so.

Dogs can be a valuable asset to the homeless, providing a friend and companion in what may otherwise prove an isolating and trustless way of life. It is not acceptable that they can prevent a homeless person from accessing health care or finding accommodation.

\section{REFERENCES}

Baker, O. 2001. A Dog's Life. Homeless People and Their Pets. Oxford: Blue Cross

Ballintyne, S. 1999. Unsafe Streets: Street Homelessness and Crime. London: Institute for Public Policy Research

Communities and Local Government. 2011. Statutory Homelessness: March Quarter 2011 England (ISBN 9781409825630) 
Crisis. 2002. Statistics about homelessness. London: Crisis

Crisis. 2011. Statistics about homelessness. London: Crisis

Davis, H., Balfour, D. 1992. The Inevitable Bond: Examining Scientist-Animal

Interactions. New York: Cambridge University Press

Dogs Trust Hope Project. 2007. Happy and Healthy: A Guide to owners who are homeless or in housing crisis. Retrieved from:

https://www.moretodogstrust.org.uk/downloads/Happy-\&Healthy-2007-FINAL.pdf Accessed January, 2016.

Edney, A.T. 1993. Dogs and human epilepsy. Veterinary Record 132: 337-338

Fitzpatrick, S., Kemp, P. and Klinker, S. 2000. Single Homelessness: An Overview of Research in Britain. Bristol: Policy Press

Homeless Link. 2009. Survey of Needs and Provision (SNAP)

Kidd, A. H. and Kidd, R. M. 1994. Benefits and liabilities of pets for the homeless. Psychological Reports 74:715-722

Labreque, J., Walsh, C. A. 2011. Homeless Women's Voices on Incorporating Companion Animals into Shelter Services. Anthrozoos 24: 79-95

Laflamme, D.P. 1997. Development and validation of a body condition score system for dogs. Canine Practice 22: $10-15$

Menteith, C. 2001. The Last Hope. Dogs Today April:9094

ONS (Office for National Statistics). 2010. Life expectancy statistics. Retrieved from:

http://www.ons.gov.uk/ons/rel/health-ineq/trend-in-lifeexpectancy-by-socioeconomic-position-by-the-national- statistics-socioeconomic-classification--england-andwales/1982-86-to-2007-11/stb-trend-in-life-expectancy.html Accessed at December, 2015.

Rew, L. 2000. Friends and pets as companions: Strategies for coping with loneliness among homeless youth. Journal of Child and Adolescent Psychiatric Nursing 13:125-132

Robinson, I. 1997. Health Benefits from Companion Animals. Melton Mowbray: Waltham Centre for Pet Nutrition

Russow, L. M. 2002. Ethical Implications of the HumanAnimal Bond in the Laboratory. Institute for Laboratory Animal Research Journal 43(1): 33-37

Sakelaropoulos, K., Davey, Bl and Knight, M. 1998. Pets and homeless people in Nottingham - the issues. Nottingham: PATH - People and Animals Together in Health

SCAS (The Society for Companion Animals Studies). 1999. The therapeutic values of companion animals in society. Veterinary Practice Nurse 11:7-8

Serpell, J. A. 1991. Beneficial effects of pet ownership on some aspects of human health and behaviour. Journal of the Royal Society of Medicine 84: 717-720

Thames Reach, 2015. Retrieved from:

http://www.thamesreach.org.uk/news-andviews/homelessness-facts-and-figures/ Accessed January, 2016.

Taylor, H., Williams, P. and Gray, D. 2004. Homelessness and dog ownership: an investigation into animal empathy, attachment, crime, drug use, health and public opinion. Anthrozoos 17: 353-368

Wilson, C. C. and Turner, D. C. 1998. Companion animals in human health. London: Sage Publications

WSAVA 2013. Retrieved from:

http://www.wsava.org/sites/default/files/Body\%20condition \%20score\%20chart\%20dogs.pdf Accessed January, 2016. 